\title{
Differential expression of carbohydrate antigen 19-9 in human colorectal cancer: A comparison with colon and rectal cancers
}

\author{
SHUAI ZHANG ${ }^{1,2^{*}}$, YIJUN CHEN ${ }^{1,2^{*}}$, ZHANMENG ZHU $^{1,2}$, YUNLONG DING $^{1,2}$, \\ SHUANGYI REN ${ }^{1}$ and YUNFEI ZUO ${ }^{2}$ \\ ${ }^{1}$ Department of General Surgery, The Second Affiliated Hospital of Dalian Medical University, Dalian, Liaoning 116023; \\ ${ }^{2}$ Department of Clinical Biochemistry, Dalian Medical University, Dalian, Liaoning 116044, P.R. China
}

Received May 11, 2013; Accepted August 12, 2013

DOI: $10.3892 / \mathrm{mco} .2013 .173$

\begin{abstract}
Colorectal cancer is one of the leading causes of cancer-related mortality, being the third most commonly diagnosed cancer among men and the second among women. Accumulating evidence regarding carbohydrate antigen (CA) demonstrated that tumor-associated antigens are clinically useful for the diagnosis, staging and monitoring of human gastrointestinal cancers, particularly colorectal cancer. There has been an extensive investigation for sensitive and specific markers of this disease. Currently, the gastrointestinal cancer-associated carbohydrate antigen 19-9 (CA19-9) is the most widely applied tumor marker in cancer diagnosis. Despite a similar etiology and cancer incidence rates, there are anatomical and clinical differences between colon and rectal cancer, as well as differences regarding tumor progression and adjuvant treatments. To investigate whether CA19-9 is differentially expressed between colon and rectal cancer, we conducted a differential analysis of serum CA19-9 levels among 227 cases of colorectal cancer, analyzing gender, age, Dukes' stage and distant metastasis for human colon and rectal cancer as a single entity, separately and as matched pairs. We demonstrated that the serum CA19-9 levels in colorectal cancer were upregulated in advanced stages with distant metastasis. By contrast, the serum CA19-9 levels in colon cancer displayed a differential and upregulated behavior in advanced stages with distant metastasis. By analyzing as
\end{abstract}

Correspondence to: Professor Shuangyi Ren, Department of General Surgery, The Second Affiliated Hospital of Dalian Medical University, 467 Zhongshan Road, Dalian, Liaoning 116023, P.R. China

E-mail: rsydl@aliyun.com

Professor Yunfei Zuo, Department of Clinical Biochemistry, Dalian Medical University, 9 Lushun South Road West Section, Dalian, Liaoning 116044, P.R. China

E-mail: zyf04112002@aliyun.com

*Contributed equally

Key words: carbohydrate antigen 19-9, colorectal cancer, tumor marker matched pairs, the upregulated serum CA19-9 levels in rectal cancer during the early stages without distant metastasis further supported our hypothesis that the expression of CA19-9 displays a site-specific differential behavior. The integrative analysis suggested a significant difference between human colon and rectal cancer, justifying individualized therapy for these two types of cancer.

\section{Introduction}

Colorectal cancer is one of the leading causes of cancer-related mortality, being the third most commonly diagnosed cancer among men and the second among women (1). The incidence rates of colorectal cancer are rapidly increasing in several areas that were historically at minimal risk, including several countries within Eastern Asia (2). Early diagnosis and intervention may be crucial in improving therapeutic effectiveness and prolonging survival time. In the initial stage of tumorigenesis, tumor markers are widely used for diagnosis, staging, and monitoring of colorectal cancer in clinical laboratory tests (3). These markers are usually proteins released from dying tumor cells or produced by neoplastic cells. Certain specific proteins are expressed only in tumor cells and are useful for the detection and diagnosis of specific malignant tumors. Non-specific proteins or markers associated with malignant tumor cells are oncofetal or carcinogenic antigens, such as carcinoembryonic antigen (CEA), $\alpha$-fetoprotein, carbohydrate antigen 125, carbohydrate antigen 19-9 (CA19-9), tissue plasminogen activator and tissue polypeptide-specific antigen (4).

Koprowski et al (5) described CA19-9 as a monoclonal antibody in 1979. Since then, CA19-9 has been increasingly used to detect serum antigens associated with specific malignancies. It was previously demonstrated that CA19-9 is produced by adenocarcinomas of the pancreas, stomach, gallbladder, colon, ovary and lung and is released into the circulation. Elevated serum CA19-9 levels have been associated with a range of gastrointestinal malignant tumors, including colorectal carcinoma. CA19-9 may also be useful in determining the nature of pancreatic masses (6). Tumor markers are most useful for monitoring the response to therapy and detecting early relapses. Each tumor marker has a variable range of application for screening, determining diagnosis and prognosis, assessing the response to therapy and monitoring 
cancer recurrence. CEA is most frequently used to detect gastrointestinal malignant tumors and the variation of CEA values reflects individual response to clinical therapy (7). By contrast, in the screening of gastrointestinal malignancies, the American Society of Clinical Oncology guidelines suggested that serum testing for CA19-9 is an integral part of the diagnosis and management of colorectal carcinomas (8). Numerous studies addressed the potential utility of CA19-9 assessment in adenocarcinomas of the colon and rectum (9). The reported incidence of elevated serum CA19-9 levels in colorectal cancer ranges from $20-40 \%$ (10). The incidence of elevated CA19-9 levels is stage-related, with the highest sensitivity observed in patients with metastases. However, the sensitivity of CA19-9 has always been lower compared to that of the CEA for all the stages of this disease. The false-positive rate is $15-30 \%$ in patients with non-neoplastic diseases of the pancreas, liver and biliary tract. Consequently, CA19-9 may not be used for screening asymptomatic populations $(11,12)$. Serum screening tests require sufficient specificity and high sensitivity to detect early-stage carcinoma. Individuals who undergo serum tests display varying results. Benign conditions, such as cirrhosis, cholestasis, cholangitis and pancreatitis, may also result in an elevation of the CA19-9 levels. False-positive results prompt the research for more specific and sensitive tumor markers.

Colorectal cancer is a major contributor to cancer-related mortality and morbidity (1). The diagnosis and therapy of colon and rectal cancer as a single entity has attracted considerable attention. Although these two types of cancer have similar etiology, incidence rates, surgical and radiotherapeutic management implications, accumulating evidence reveals notable differences. The differences between the colon and rectum are largely anatomical and biological and may affect prognosis. Cancers of the colon and rectum may develop differently due to their distinctive embryological origin (midgut/hindgut and hindgut, respectively) and differential exposure to bowel content. Furthermore, colon and rectal cancers have differences regarding anatomy and blood circulation. Venous blood from the colon flows to the liver via the portal vein, whereas rectal venous blood partially bypasses the liver. Blood circulation often affects tumor relapse. Rectal cancers exhibit higher rates of localized regional relapse and lung metastases, whereas colon cancers have a higher tropism for liver spread (13). The serum concentration of tumor markers may be affected by metabolism in the liver. This may explain the differential expression of CA19-9 between these two malignancies. There is also a difference in clinical presentation, prognosis and, possibly, in genetic and environmental epidemiology (14). The differential behavior of single molecules in colon and rectal tumors may help elucidate the molecular basis of these two types of cancer and their prognostic and therapeutic implications (15). Despite clinical evidence of the differences between colon and rectal cancer, the number of studies that have addressed the molecular differences between the two diseases is limited. Through the analysis of several molecular markers, Kapitejin et al (16) demonstrated a significantly different $\beta$-catenin and p53 expression between colon and rectal cancers and concluded that these two malignancies may follow different mechanisms of oncogenesis (17). Furthermore, the analysis of KRAS mutations revealed that they are more specifically detectable in colon compared to rectal cancer (18). As regards epidemiological, morphological and molecular characteristics, the mechanisms of colorectal carcinogenesis may differ according to tumor location. It was suggested that a mechanism exists that promotes the progression of mucosal lesions to invasive cancers in the colon and rectum (19). Therefore, we decided to investigate whether there are differences in the serum levels of CA19-9 between patients with colon and those with rectal cancer.

In our study, a differential analysis of serum CA19-9 levels according to gender, age, Dukes' stage and distant metastasis for human colon and rectal cancer was conducted. As a significant predictor for colorectal cancer invasion and metastasis, serum CA19-9 levels in colon cancer displayed a notable upregulated behavior in advanced stages of the tumor with distant metastasis. By contrast, the upregulated serum CA19-9 levels in the early stages of rectal cancer without distant metastasis further supported our hypothesis that the expression of CA19-9 displayed a site-specific differential behavior. The integrative analysis suggested a significant difference between colon and rectal cancer and also indicated an important role for CA19-9 in early diagnosis and individualized therapy of human colorectal cancer.

\section{Materials and methods}

Patient specimens. Preoperative serum samples were obtained from 227 patients (135 men and 92 women) with histologically verified colorectal cancer. The patients were classified into the younger group ( $<60$ years old, 90 cases) and the elder group ( $\geq 60$ years old, 137 cases). As the focus of our study, 116 colon and 111 rectal cancers were staged according to the modified Dukes' classification (stage A, 54; stage B, 51; stage C, 57; and stage D, 65 cases). As mentioned above, 116 patients had colon cancer (30 patients had stage A, 28 stage B, 28 stage $C$ and 30 stage D) and 111 patients had rectal cancer (24 patients had stage A, 23 stage B, 29 stage $C$ and 35 stage D). According to our statistics, specimens with Dukes' stage A, B and C colorectal cancer did not exhibit significant differences. However, patients with Dukes' stage D disease were quite different. Therefore, patients with Dukes'stages A-C were considered as having early-stage disease, whereas those with Dukes' stage D were considered as having advanced-stage disease. Patients in the distant metastasis group had either lymph node or distant metastases. The CA19-9 values were obtained from the serum of the patients who underwent surgical resection at the First and Second Affiliated Hospitals of Dalian Medical University beteween 2010 and 2012 .

Serum collection and CA19-9 assay. The preoperative serum samples were obtained prior to the administration of radiation treatment or chemotherapy. Blood samples were collected, separated by centrifugation and the serum samples were stored at $-20^{\circ} \mathrm{C}$ until the assays were performed. The CA19-9 kit was provided by Diagnostic Products Corporation (DPC, Tianjin, China). The serum CA19-9 levels were determined by the DPC Gamma C12 immunoradiometric gamma counter (DPC). Data on patient specimens were furnished by the First and Second Affiliated Hospitals of Dalian Medical University between 2010 and 2012 . 
Table I. Comparison of serum CA19-9 levels in colorectal cancer among different groups.

\begin{tabular}{lrcr}
\hline $\begin{array}{l}\text { Pathological } \\
\text { characteristics }\end{array}$ & No. & $\begin{array}{c}\text { Median } \\
\text { CA19-9 (U/ml) }\end{array}$ & P-value \\
\hline $\begin{array}{l}\text { Gender } \\
\text { Male }\end{array}$ & 135 & 15.30 & 0.615 \\
$\quad \begin{array}{l}\text { Female } \\
\text { Age (years) }\end{array}$ & 92 & 13.48 & \\
$\quad<60$ & 90 & 14.65 & 0.665 \\
$>60$ & 137 & 14.20 & \\
$\begin{array}{l}\text { Dukes' stage } \\
\text { Early }\end{array}$ & 162 & 12.75 & $0.005^{\mathrm{a}}$ \\
$\quad$ Advanced & 65 & 18.64 & \\
$\begin{array}{l}\text { Distant metastasis } \\
-\end{array}$ & 161 & 12.70 & $0.016^{\mathrm{a}}$ \\
+ & 66 & 18.06 & \\
\hline
\end{tabular}

aStatistically significant. CA19-9, carbohydrate antigen 19-9.

Statistical analysis. A differential analysis of the 227 samples according to serum CA19-9 levels, gender, age, Dukes' stage and metastasis was separately conducted for human colon and rectal cancer. The serum levels of CA19-9 did not follow a normal distribution and the significance between the groups was calculated by non-parametric statistical methods (Mann-Whitney and Kruskall-Wallis tests). The centralized tendency of each group was described by geometric mean due to the right skewness of the frequency distribution. The statistical analysis was performed with SPSS software for Windows, version 11.5 (SPSS Inc., Chicago, IL, USA). Our results were accurate to four digits. $\mathrm{P}<0.05$ was considered to indicate a statistically significant difference.

\section{Results}

Upregulated serum CA19-9 levels in colorectal cancer with advanced stage and distant metastasis. A total of 227 colorectal cancer patients, including 116 colon and 111 rectal cancer cases, were clinically diagnosed by imaging and histopathology. For the mean values (mean \pm SEM) of the CA19-9 levels, there was no statistical difference between the sera collected from colon cancer $(45.85 \pm 11.05 \mathrm{U} / \mathrm{ml})$ and those collected from rectal cancer patients $(44.88 \pm 9.150 \mathrm{U} / \mathrm{ml})(\mathrm{P}=0.9467)$. Therefore, we analyzed them first as a single entity (Table I and Fig. 1). We observed that the serum CA19-9 levels between the gender groups (135 men and 92 women) and the age groups (90 patients included in the younger and 137 patients in the elder group) exhibited no statistically significant difference ( $\mathrm{P}>0.05)$. However, the mean values of serum CA19-9 levels exhibited a significant correlation with Dukes' stage $(\mathrm{P}=0.005)$ and distant metastasis $(\mathrm{P}=0.016)$. The mean values of the serum CA19-9 levels in patients with advanced-stage disease $(74.30 \pm 11.29 \mathrm{U} / \mathrm{ml})$ and distant metastasis $(71.33 \pm 18.49 \mathrm{U} / \mathrm{ml})$ were more upregulated compared to those in patients with
227 CRC specimens

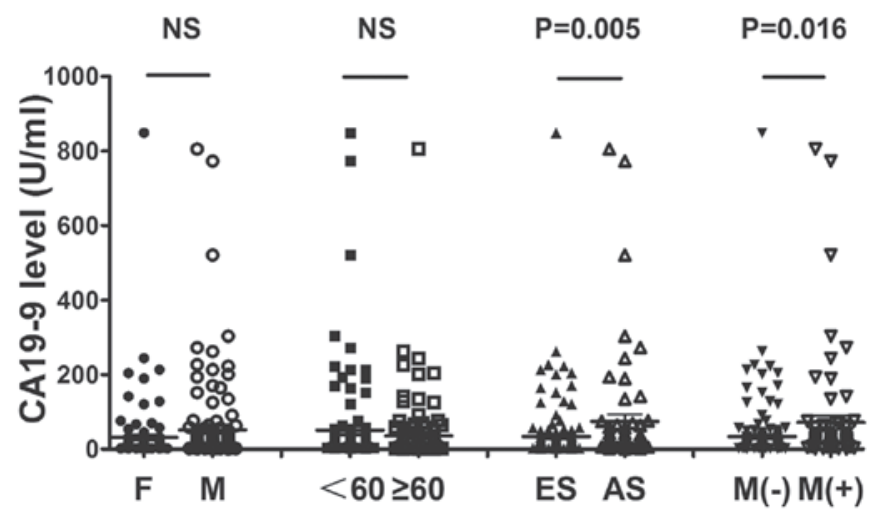

Figure 1. Different mean values of carbohydrate antigen 19-9 (CA19-9) among the 227 CRC specimens according to different groups. The $227 \mathrm{CRC}$ specimens were divided into 4 groups according to gender, age $(<60$ and $\geq 60$ years), Dukes' stage and metastasis. Although patients with different gender and age, exhibited no statistically significant differences, the differences between patients with early- and advanced-stage disease $(\mathrm{P}=0.005)$ and between patients with and those without metastasis $(\mathrm{P}=0.016)$ were statistically significant. The results indicated that high CA19-9 values were more significant for patients with Dukes' stage D disease or with metastasis. Furthermore, the expression of CA19-9 was increased during tumorigenesis. CRC, colorectal cancer; F, female; $\mathrm{M}$, male; $<60$, patients younger than 60 years; $\geq 60$, patients older than 60 years; ES, early stage (Dukes' A, B and C); AS, advanced stage (Dukes' D); M(-), patients without metastasis; $\mathrm{M}(+)$, patients with metastasis; NS, difference without statistical significance.

early-stage disease $(33.77 \pm 6.284 \mathrm{U} / \mathrm{ml})$ and without distant metastasis $(33.86 \pm 6.322 \mathrm{U} / \mathrm{ml})$. The expression of CA19-9 exhibited a tendency for increase, suggesting that the mean values of serum CA19-9 levels reflected tumor progression and were a significant predictor for colorectal carcinoma invasion and metastasis (Table I and Fig. 1). This finding may be associated with the function of CA19-9 in the differentiation and migration of tumor cells.

Upregulated serum CA19-9 levels in colon cancer, but not in rectal cancer, with advanced stage and distant metastasis. A number of studies indicated the differences between colon and rectal cancer $(14,16,21,24)$; therefore, we conducted further separate analyses of the serum CA19-9 levels in colon and rectal cancer (Tables II and III, Fig. 2). In colon cancer specimens, the results demonstrated that the serum CA19-9 levels in colon cancer were significantly correlated with Dukes' tumor stage $(\mathrm{P}=0.002)$ and distant metastasis $(\mathrm{P}=0.003)$. The upregulated gradient of CA19-9 levels was quite notable. The mean CA19-9 values in patients with advanced-stage disease $(113.7 \pm 25.32 \mathrm{U} / \mathrm{ml})$ and distant metastasis $(111.1 \pm 25.03 \mathrm{U} / \mathrm{ml})$ were significantly higher compared to those in patients with early-stage disease $(19.86 \pm 2.468 \mathrm{U} / \mathrm{ml})$ and without distant metastasis $(19.77 \pm 2.481 \mathrm{U} / \mathrm{ml})$. Similar to the holistic analyses of colorectal cancer, the differences in colon cancer specimens between gender and age groups were not statistically significant. We confirmed that CA19-9 expression in colon cancer patients was significantly upregulated during the process of tumorigenesis and metastasis (Table II and Fig. 2A). However, the mean values of serum CA19-9 levels in rectal cancer displayed no statistically significant difference among any of the 4 groups (Table III and Fig. 2B). This finding indicated 
Table II. Comparison of serum CA19-9 levels in colon cancer among different groups.

\begin{tabular}{lccc}
\hline $\begin{array}{l}\text { Pathological } \\
\text { characteristics }\end{array}$ & No. & $\begin{array}{c}\text { Median } \\
\text { CA19-9 }(\mathrm{U} / \mathrm{ml})\end{array}$ & P-value \\
\hline $\begin{array}{l}\text { Gender } \\
\text { Male }\end{array}$ & 68 & 12.55 & 0.960 \\
Female & 48 & 12.35 & \\
Age (years) & & & 0.522 \\
$<60$ & 42 & 10.03 & \\
$>60$ & 74 & 13.28 & \\
$\begin{array}{l}\text { Dukes' stage } \\
\text { Early }\end{array}$ & 86 & 11.38 & $0.002^{\mathrm{a}}$ \\
Advanced & 30 & 28.99 & \\
Distant metastasis & & & $0.003^{\mathrm{a}}$ \\
- & 84 & 11.38 & \\
+ & 32 & 26.38 & \\
\hline
\end{tabular}

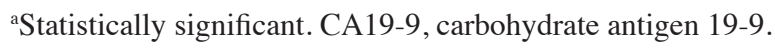

Table III. Comparison of serum CA19-9 levels in rectal cancer among different groups.

\begin{tabular}{lccc}
\hline $\begin{array}{l}\text { Pathological } \\
\text { characteristics }\end{array}$ & No. & $\begin{array}{c}\text { Median } \\
\text { CA19-9 }(\mathrm{U} / \mathrm{ml})\end{array}$ & P-value \\
\hline Gender & & & 0.583 \\
$\quad$ Male & 67 & 17.11 & \\
Female & 44 & 14.77 & \\
Age (years) & & & 0.270 \\
$\quad<60$ & 48 & 16.98 & \\
$>60$ & 63 & 15.30 & \\
Dukes' stage & & & 0.570 \\
$\quad$ Early & 76 & 15.21 & \\
Advanced & 35 & 17.35 & 0.452 \\
Distant metastasis & & & \\
- & 77 & 15.11 & \\
+ & 34 & 17.41 &
\end{tabular}

CA19-9, carbohydrate antigen 19-9.
A

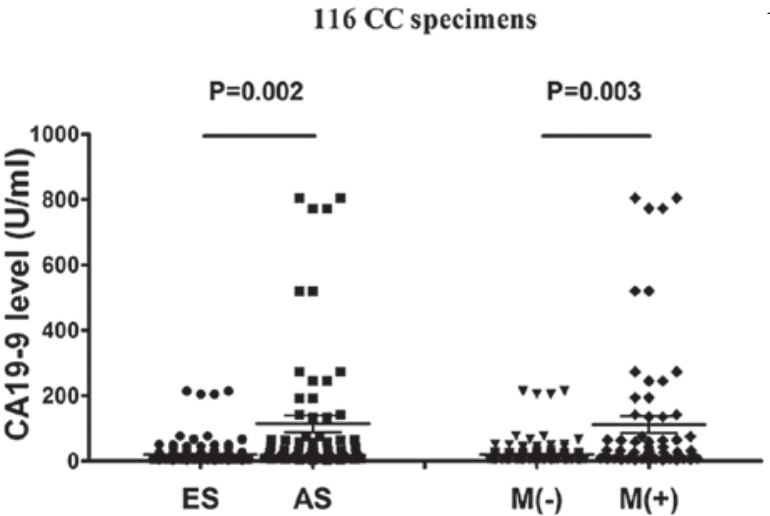

B

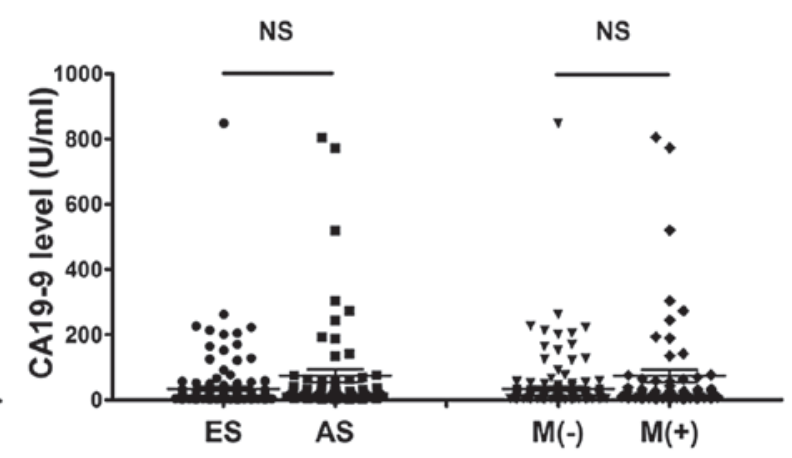

Figure 2. Different mean values of carbohydrate antigen 19-9 (CA19-9) among the 116 CC and the 111 RC specimens separately. The 227 CRC specimens included $116 \mathrm{CC}$ and $111 \mathrm{RC}$ patients. The $116 \mathrm{CC}$ and $111 \mathrm{RC}$ specimens were separately divided into 4 groups according to gender, age ( $<60$ and $\geq 60$ years), Dukes' stage and metastasis. (A) The differences between early- and advanced-stage disease ( $\mathrm{P}=0.002)$ and the differences between patients with and those without metastasis $(\mathrm{P}=0.003)$ in the $116 \mathrm{CC}$ specimens were statistically significant. There were no significant differences regarding the remaining two variables. (B) Among the $111 \mathrm{RC}$ patients divided into the 4 different groups, there were no statistically significant differences in the mean CA19-9 values. CC, colon cancer; RC, rectal cancer; CRC, colorectal cancer; $<60$, patients younger than 60 years; $\geq 60$, patients aged 60 years or older; ES, early stage (Dukes' A, B and C); AS, advanced stage (Dukes' D); M(-), patients without metastasis; M(+), patients with metastasis; NS, difference without statistical significance.

that CA19-9 expression was not only associated with invasion and metastasis, but also varied with tumor location. The mean CA19-9 values in patients with advanced-stage disease $(74.30 \pm 19.27 \mathrm{U} / \mathrm{ml})$ and distant metastasis $(73.48 \pm 19.00 \mathrm{U} / \mathrm{ml})$ were significantly higher compared to those in patients with early-stage disease $(33.75 \pm 6.284 \mathrm{U} / \mathrm{ml})$ and without distant metastasis $(33.86 \pm 6.322 \mathrm{U} / \mathrm{ml})$.

Differential expression of serum CA19-9 levels between colon and rectal cancer in early-stage disease without distant metastasis. Previous studies indicated that colon and rectal cancer were similar but different types of cancer $(14,16,24,26)$. Therefore, we continued our study by analyzing colon and rectal cancer as matched pairs (Table IV and Fig. 3). According to our statistical data, the mean values of serum CA19-9 levels in early-stage disease $(\mathrm{P}=0.015)$ and without distant metastasis $(\mathrm{P}=0.021)$ were significantly more upregulated in rectal compared to colon cancer, with a statistically significant difference (Table IV and Fig. 3B). There was no distinction between colon and rectal cancer in the cohort with gender and age groups (Table IV and Fig. 3A). However, the serum CA19-9 levels in rectal cancer patients with early-stage disease (76 patients) was significantly more upregulated compared to those in colon cancer patients with the same Dukes' stage (86 patients) $(\mathrm{P}=0.015)$. In addition, the CA19-9 levels in rectal cancer patients without distant metastasis (including 84 colon cancer and 77 rectal cancer patients) was also statistically more upregulated compared to those in colon cancer patients in the same matched pairs $(\mathrm{P}=0.021)$ (Table IV 
Table IV. Comparison of serum carbohydrate antigen 19-9 (CA19-9) levels between colon and rectal cancer.

\begin{tabular}{|c|c|c|c|c|c|}
\hline \multirow{2}{*}{$\begin{array}{l}\text { Pathological } \\
\text { characteristics }\end{array}$} & \multicolumn{2}{|c|}{ Cases } & \multicolumn{2}{|c|}{ Median CA19-9 (U/ml) } & \multirow[b]{2}{*}{ P-value } \\
\hline & Colon cancer & Rectal cancer & Colon cancer & Rectal cancer & \\
\hline \multicolumn{6}{|l|}{ Gender } \\
\hline Male & 68 & 67 & 12.55 & 17.11 & 0.165 \\
\hline Female & 48 & 44 & 12.35 & 14.77 & 0.298 \\
\hline \multicolumn{6}{|l|}{ Age (years) } \\
\hline$<60$ & 42 & 48 & 10.03 & 16.98 & 0.075 \\
\hline$>60$ & 74 & 63 & 13.28 & 15.30 & 0.433 \\
\hline \multicolumn{6}{|l|}{ Dukes' stage } \\
\hline Early & 86 & 76 & 11.38 & 15.21 & $0.015^{\mathrm{a}}$ \\
\hline Advanced & 30 & 35 & 28.99 & 17.35 & 0.231 \\
\hline \multicolumn{6}{|c|}{ Distant metastasis } \\
\hline- & 84 & 77 & 11.38 & 15.11 & $0.021^{\mathrm{a}}$ \\
\hline+ & 32 & 34 & 26.38 & 17.41 & 0.346 \\
\hline
\end{tabular}

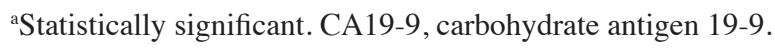

\section{CRC specimens}

A

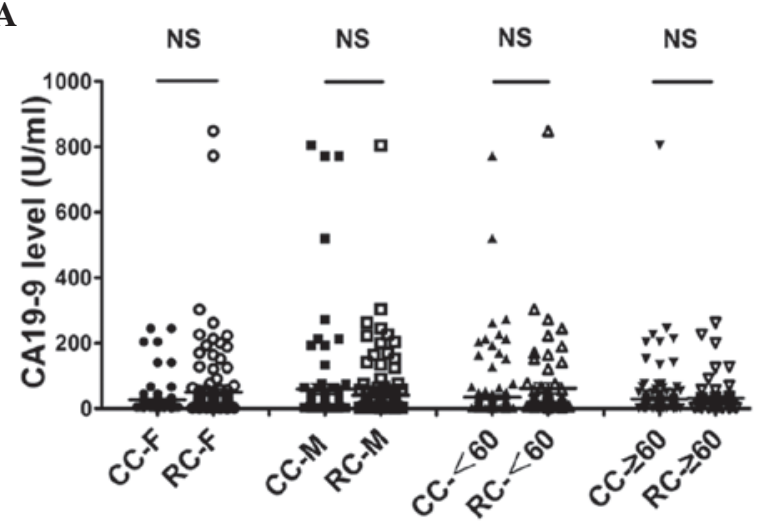

B $P=0.015$

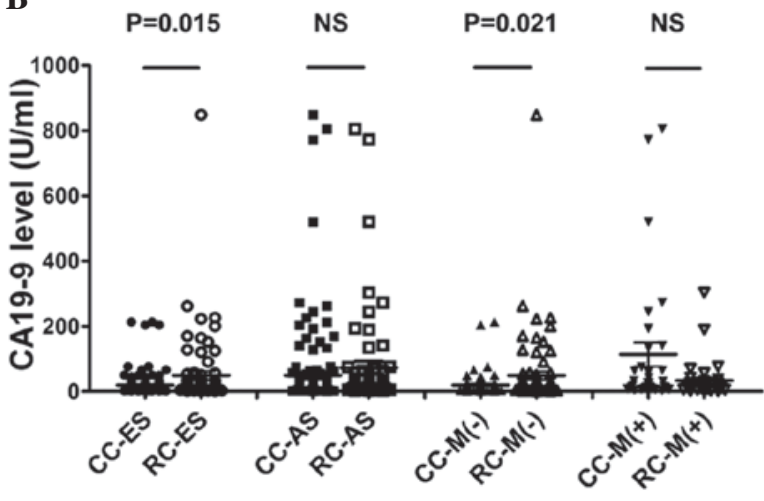

Figure 3. Different mean values of carbohydrate antigen 19-9 (CA19-9) between CC and RC patients according to gender, age, Dukes' stage and metastasis. A total of 227 CRC patients, including $116 \mathrm{CC}$ and $111 \mathrm{RC}$ patients, were divided into 4 groups according to gender, age ( $<60$ and $\geq 60$ years), Dukes' stage and metastasis. Furthermore, CA19-9 values were compared between CC and RC as different aspects of tumor location. Among the patients of different gender and age, female RC and male CC patients exhibited a tendency for high CA19-9 levels. Of note, the two age groups exhibited high mean CA19-9 values in RC patients. However, there were no significant differences in the mean CA19-9 values between gender and age difference groups (A) Among the patients with advanced Dukes' stage and metastasis, although CC patients exhibited higher CA19-9 levels compared to RC patients during the same period, the differences were not statistically significant. Among these 4 groups, we demonstrated that RC patients with early-stage disease $(\mathrm{P}=0.0015)$ and without metastasis $(\mathrm{P}=0.0021)$ exhibited statistically significant higher mean CA19-9 values compared to CC patients. CC, colon cancer; RC, rectal cancer; CRC, colorectal cancer; F, female; M, male; <60, patients younger than 60 years; $\geq 60$, patients aged 60 years or older; ES, early stage (Dukes' A, B and C); AS, advanced stage (Dukes' D); M(-), patients without metastasis; M(+), patients with metastasis; NS, difference without statistical significance.

and Fig. 3B). These results demonstrated that the expression of CA19-9 displayed a site-specific differential behavior. Moreover, they suggested that serum CA19-9 levels may be more sensitive in the early diagnosis of rectal cancer. The differential expression of CA19-9 during the early stages of tumorigenesis also indicates the distinction between colon and rectal carcinomas.

\section{Discussion}

Similar to other tumor-associated antigens, it appears that elevated serum CA19-9 levels are associated with gastrointestinal malignancies, particularly advanced colorectal cancer. Of more relevance to the potential use of CA19-9 as a screening test is the comparison of CA19-9 serum levels between individuals with colon and rectal cancer. To identify possible biological differences between colon and rectal tumors, we conducted a differential analysis of 227 specimens, analyzing serum CA19-9 levels according to gender, age, Dukes' stage and distant metastasis in human colon and rectal cancer. We demonstrated that the serum CA19-9 levels in colorectal cancer of advanced stage and with distant metastasis were significantly upregulated, suggesting that the 
expression of CA19-9 reflects tumor invasion and metastasis. Correspondingly, we confirmed that serum CA19-9 levels displayed a notable upregulation in colon cancer specimens of advanced stage and with distant metastasis. However, we failed to demonstrate this upregulation of CA19-9 in rectal cancer specimens, suggesting that colon and rectal cancer are similar but different types of cancer. In our continued comparison, by analyzing colon and rectal cancer as matched pairs, the serum CA19-9 levels in early-stage disease and without distant metastasis exhibited statistically more significant upregulation in rectal compared to colon cancer. It was evident that there was no distinction between colon and rectal cancer in the cohort of gender and age groups. These results further supported our hypothesis that the expression of CA19-9 displayed a site-specific behavior.

The issue of whether colon and rectal cancer should be considered as a single entity or two distinct entities is still debated upon. There are differences between colon and rectal cancer with respect to patient gender and age, as well as tumor progression and adjuvant treatments (17). Despite a similar etiology and cancer incidence rates, the anatomical and clinical distinction should not be overlooked. A previous study attempted to identify and characterize the genetic changes involved in the colorectal malignant transformation process (18). Through the analysis of several molecular markers, Kapitejin et al demonstrated a significantly different $\beta$-catenin and p53 expression between colon and rectal cancers and concluded that these two types of cancer may follow separate mechanisms of oncogenesis (16). Furthermore, several critical genes and pathways have been shown to be involved in the initiation and progression of colorectal cancer. Large-scale sequencing analyses identified numerous recurrently mutated genes and a recurrent chromosomal translocation (20-22). These include the cyclin A2, COX2, RAS-MAPK, PI3K, TGF- $\beta$, p53 and DNA mismatch-repair pathways (22). Moreover, colon cancers exhibit a higher number of mutations, including KRAS and BRAF mutations (15). The CIN pathway is far more common in rectal compared to colon cancers $(24,25)$. In addition, several homeobox genes were found to be associated with tumor location (26). A different number of mutations induce varying mechanisms of oncogenesis in colon and rectal cancer. The site-specific differential behavior of CA19-9 in colon and rectal carcinoma demonstrated a different tumor identification and progression.

It was previously demonstrated that the serum CA19-9 levels were the most significant prognostic indicator of patients with metastatic colorectal cancer (27). Our results, although similar, differed in detail. The serum CA19-9 levels were significantly upregulated in association with advanced-stage disease and distant metastasis in colon cancer, but not in rectal cancer. In our continued study, serum CA19-9 levels in early-stage disease and without distant metastasis were statistically significantly more upregulated in rectal cancer compared to colon cancer, suggesting that CA19-9 is more sensitive for early diagnosis of rectal cancer. The differential expression of CA19-9 between colon and rectal cancer further supports that colon and rectal cancer are similar but different types of cancer.

In conclusion, our study strongly suggests that the expression of CA19-9 displays a site-specific differential behavior.
The internal mechanism underlying our results has not been elucidated, although a consistent difference was observed between colon and rectal cancer. This observation indicates an important role for CA19-9 in early diagnosis and tumor metastasis. In our future study, we aim to recommend the individualization of treatment for human colon and rectal cancer.

\section{Acknowledgements}

This study was supported by a grant from NSFC (31270867), Chinese State Key Program in Basic Research (2012CB822103) and Hall of Liaoning Province Science and Technology Grant (2012225020).

\section{References}

1. Weitz J, Koch M, Debus J, Höhler T, Galle PR and Büchler MW: Colorectal cancer. Lancet 365: 153-165, 2005.

2. Jemal A, Bray F, Center MM, Ferlay J, Ward E and Forman D: Global cancer statistics. CA Cancer J Clin 61: 69-90, 2011.

3. Ludwig JA and Weinstein JN: Biomarkers in cancer staging, prognosis and treatment selection. Nat Rev Cancer 5: 845-856, 2005 .

4. Chan CC, Fan CW, Kuo YB, Chen YH, Chang PY, Chen KT, Hung RP and Chan EC: Multiple serological biomarkers for colorectal cancer detection. Int J Cancer 126: 1683-1690, 2010.

5. Koprowski H, Steplewski Z, Mitchell K, Herlyn M, Herlyn D and Fuhrer P: Colorectal carcinoma antigens detected by hybridoma antibodies. Somatic Cell Genet 5: 957-971, 1979.

6. Goonetilleke KS and Siriwardena AK: Systematic review of carbohydrate antigen (CA 19-9) as a biochemical marker in the diagnosis of pancreatic cancer. Eur J Surg Oncol 33: 266-270, 2007.

7. Yakabe T, Nakafusa Y, Sumi K, Miyoshi A, Kitajima Y, Sato S, Noshiro H and Miyazaki K: Clinical significance of CEA and CA19-9 in postoperative follow-up of colorectal cancer. Ann Surg Oncol 17: 2349-2356, 2010.

8. Bast RC Jr, Ravdin P, Hayes DF, Bates S, Fritsche H Jr, Jessup JM, Kemeny N, Locker GY, Mennel RG and Somerfield MR; American Society of Clinical Oncology Tumor Markers Expert Panel: 2000 update of recommendations for the use of tumor markers in breast and colorectal cancer: clinical practice guidelines of the American Society of Clinical Oncology. J Clin Oncol 19: 1865-1878, 2001.

9. Duffy MJ, van Dalen A, Haglund C, Hansson L, Klapdor R, Lamerz R, Nilsson O, Sturgeon C and Topolcan O: Clinical utility of biochemical markers in colorectal cancer: European Group on Tumour Markers (EGTM) guidelines. Eur J Cancer 39: 718-727, 2003.

10. Gupta MK, Arciaga R, Bocci L, Tubbs R, Bukowski R and Deodhar SD: Measurement of a monoclonal-antibody-defined antigen (CA19-9) in the sera of patients with malignant and nonmalignant diseases. Comparison with carcinoembryonic antigen. Cancer 56: 277-283, 1985.

11. Thomas WM, Robertson JF, Price MR and Hardcastle JD: Failure of CA19-9 to detect asymptomatic colorectal carcinoma. Br J Cancer 63: 975-976, 1991.

12. Iemura $\mathrm{K}$ and Moriya Y: A comparative analysis of the serum levels of NCC-ST-439, CEA and CA19-9 in patients with colorectal carcinoma. Eur J Surg Oncol 19: 439-442, 1993.

13. Tan KK, Lopes Gde L Jr and Sim R: How uncommon are isolated lung metastases in colorectal cancer? A review from database of 754 patients over 4 years. J Gastrointest Surg 13: 642-648, 2009.

14. Iacopetta B: Are there two sides to colorectal cancer? Int J Cancer 101: 403-408, 2002.

15. Fearon ER: Molecular genetics of colorectal cancer. Annu Rev Pathol 6: 479-507, 2011.

16. Kapiteijn E, Liefers GJ, Los LC, Kranenbarg EK, Hermans J, Tollenaar RA, Moriya Y, van de Velde CJ and van Krieken JH: Mechanisms of oncogenesis in colon versus rectal cancer. J Pathol 195: 171-178, 2001.

17. Weissenberger C, Von Plehn G, Otto F, Barke A, Momm F and Geissler M: Adjuvant radiochemotherapy of stage II and III rectal adenocarcinoma: role of CEA and CA 19-9. Anticancer Res 25: 1787-1793, 2005. 
18. Hinoue T, Weisenberger DJ, Lange CP, Shen H, Byun HM, Van Den Berg D, Malik S, Pan F, Noushmehr H, van Dijk CM, Tollenaar RA and Laird PW. Genome-scale analysis of aberrant DNA methylation in colorectal cancer. Genome Res 22: 271-282, 2012.

19. Birkenkamp-Demtroder K, Olesen SH, Sørensen FB, Laurberg S, Laiho P, Aaltonen LA and Ørntoft TF: Differential gene expression in colon cancer of the caecum versus the sigmoid and rectosigmoid. Gut 54: 374-384, 2005.

20. Cui H, Cruz-Correa M, Giardiello FM, Hutcheon DF, Kafonek DR, Brandenburg S, Wu Y, He X, Powe NR and Feinberg AP: Loss of IGF2 imprinting: a potential marker of colorectal cancer risk. Science 299: 1753-1755, 2003.

21. Jorissen RN, Gibbs P, Christie M, Prakash S, Lipton L, Desai J, Kerr D, Aaltonen LA, Arango D, Kruhøffer M, Orntoft TF, Andersen CL, Gruidl M, Kamath VP, Eschrich S, Yeatman TJ and Sieber OM: Metastasis-associated gene expression changes predict poor outcomes in patients with Dukes stage B and C colorectal cancer. Clin Cancer Res 15: 7642-7651, 2009.

22. Dunican DS, McWilliam P, Tighe O, Parle-McDermott A and Croke DT: Gene expression differences between the microsatellite instability (MIN) and chromosomal instability (CIN) phenotypes in colorectal cancer revealed by high-density cDNA array hybridization. Oncogene 21: 3253-3257, 2002.
23. Ahlquist DA, Skoletsky JE, Boynton KA, Harrington JJ, Mahoney DW, Pierceall WE, Thibodeau SN and Shuber AP: Colorectal cancer screening by detection of altered human DNA in stool: feasibility of a multitarget assay panel. Gastroenterology 119: 1219-1227, 2000.

24. Frattini M, Balestra D, Pilotti S, Bertario L and Pierotti MA: Tumor location and detection of k-ras mutations in stool from colorectal cancer patients. J Natl Cancer Inst 95: 72-73, 2003.

25. Li FY and Lai MD: Colorectal cancer, one entity or three. J Zhejiang Univ Sci B 10: 219-229, 2009.

26. Sanz-Pamplona R, Cordero D, Berenguer A, Lejbkowicz F, Rennert H, Salazar R, Biondo S, Sanjuan X, Pujana MA, Rozek L, Giordano TJ, Ben-Izhak O, Cohen HI, Trougouboff P, Bejhar J, Sova Y, Rennert G, Gruber SB and Moreno V: Gene expression differences between colon and rectum tumors. Clin Cancer Res 17: 7303-7312, 2011.

27. Wang WS, Lin JK, Chiou TJ, Liu JH, Fan FS, Yen CC, Lin TC, Jiang JK, Yang SH, Wang HS and Chen PM: CA19-9 as the most significant prognostic indicator of metastatic colorectal cancer. Hepatogastroenterology 49: 160-164, 2002. 